\title{
Retrograde Blood Flow in the Aortic Arch Determined by Transesophageal Doppler Ultrasound
}

\author{
S. Svedlund ${ }^{\mathrm{a}} \quad$ R. Wetterholm ${ }^{\mathrm{a}} \quad$ R. Volkmann ${ }^{\mathrm{a}} \quad$ K. Caidahla, b \\ a Department of Clinical Physiology, Sahlgrenska University Hospital and Göteborg University, Göteborg, \\ ${ }^{b}$ Department of Molecular Medicine and Surgery, Karolinska Institutet, and Department of Clinical Physiology, \\ Karolinska University Hospital, Stockholm, Sweden
}

\section{Key Words}

Secondary prevention $\cdot$ Ischemic stroke $\cdot$ Ultrasonography • Doppler ultrasound

\begin{abstract}
Background: Aortic arch atheromas may be important sources of cerebral embolism. Aortic plaques are frequently found somewhat distal to the origin of the cerebral arteries, implying that cerebral embolization from such plaques depends on local retrograde blood flow components in this area. Therefore, we investigated the occurrence of blood flow reversal in this part of the aorta. Furthermore, since the presence and magnitude of retrograde flow might be influenced by aortic wall properties, we also studied the relationship between plaque size and distribution, aortic strain and degree of retrograde flow. Methods: We evaluated aortic arch ante- and retrograde blood flow velocities in 56 patients by transesophageal echocardiography using colorDoppler-guided pulsed-Doppler techniques. The velocitytime integrals (VTI) were measured and the diastolic/systolic VTI ratio was calculated. Results: Retrograde diastolic blood flow was noted in all subjects, and diastolic/systolic VTI ratios were higher $(p<0.05)$ in patients with plaque $\geq 4 \mathrm{~mm}$ $(n=17)$ compared to those $(n=39)$ without. Patients exhibiting plaques exclusively in the aortic arch showed the highest VTI ratios $(p<0.01)$ and tended to have the lowest strain val-
\end{abstract}

ues. Aortic strain was also reduced in patients $>50$ years of age $(p<0.01)$. Conclusions: Our findings demonstrate retrograde aortic flow in all subjects and its proportion increases in subjects with atherosclerosis, particularly in the aortic arch. Aortic plaques situated distally to the origin of the cerebral arteries are therefore possible sources of cerebral emboli.

Copyright $\odot 2008$ S. Karger AG, Basel

\section{Introduction}

Hypertension is an important risk factor for atherosclerosis and stroke, still insufficiently treated, however [1]. While hypertension with high transmural pressure may increase low-density lipoprotein concentration in the arterial wall on a global level, low shear stress leads to a focal accumulation [2]. Low shear stress is thought to play a key role when considering hemodynamic properties for atheroma development [3]. Changes in wall shear stress due to increased vorticity and unstable blood flow may also be a reason for progression of atherogenesis $[3$, 4]. Using transesophageal echocardiography (TEE), aortic atherosclerotic plaques can be identified with high reliability. Findings of plaque formations may help to determine the theoretical risk of ischemic stroke, which seems to be particularly high in patients with complex plaques $(\geq 3.5$ or $4 \mathrm{~mm})$ in the aortic arch $[5,6]$. Atherosclerosis

\section{KARGER}

Fax +41613061234 E-Mail karger@karger.ch www.karger.com
(C) 2008 S. Karger AG, Basel

1015-9770/09/0271-0022\$26.00/0

Accessible online at:

www.karger.com/ced
Dr. Kenneth Caidahl

Department of Clinical Physiology N2:01

Karolinska Institutet and Karolinska University Hospital

SE-171 76 Stockholm (Sweden)

Tel. +4685177 7510, Fax +4685177 3800, E-Mail kenneth.caidahl@ki.se 
Table 1. Clinical data of the study population and reason for referral

\begin{tabular}{|c|c|c|c|c|c|}
\hline & $\begin{array}{l}\text { All } \\
\text { patients }\end{array}$ & $\begin{array}{l}\text { Embolic } \\
\text { source }\end{array}$ & $\begin{array}{l}\text { Pulmonary } \\
\text { vein isolation }\end{array}$ & Endocarditis & Other \\
\hline Number & 56 & 30 & 9 & 6 & 11 \\
\hline $\operatorname{Sex}(M / F)$ & $36 / 20$ & $18 / 12$ & $7 / 2$ & $2 / 4$ & $9 / 2$ \\
\hline Age, years & $60.3 \pm 12.7$ & $62.5 \pm 10.2$ & $47.9 \pm 12.4$ & $66.0 \pm 12.8$ & $61.0 \pm 14.3$ \\
\hline Body mass index & $25.9 \pm 4.2$ & $26.2 \pm 5.0$ & $25.9 \pm 3.1$ & $24.6 \pm 2.8$ & $25.7 \pm 3.6$ \\
\hline High blood pressure, $\%$ & $30(17 / 56)$ & $27(8 / 30)$ & $22(2 / 9)$ & $50(3 / 6)$ & $36(4 / 11)$ \\
\hline Atrial fibrillation, $\%$ & $13(7 / 56)$ & $10(3 / 30)$ & $11(1 / 9)$ & $0(0 / 6)$ & $9(1 / 11)$ \\
\hline Ejection fraction, $\%$ & $58.3 \pm 7.5$ & $59.3 \pm 6.4$ & $58.9 \pm 7.8$ & $49.2 \pm 12.8$ & $60.0 \pm 0.0$ \\
\hline Average heart rate, beats/min & $77.4 \pm 20.2$ & $75.6 \pm 14.1$ & $73.6 \pm 14.5$ & $63.2 \pm 6.8$ & $87.2 \pm 23.4$ \\
\hline \multicolumn{6}{|l|}{ Largest plaque $<4 \mathrm{~mm} / \geq 4 \mathrm{~mm}$} \\
\hline Ascending aorta & $2 / 2$ & $0 / 1$ & $0 / 0$ & $2 / 0$ & $0 / 1$ \\
\hline Aortic arch & $6 / 14$ & $4 / 10$ & $0 / 0$ & $1 / 2$ & $1 / 2$ \\
\hline Descending aorta & $10 / 5$ & $6 / 3$ & $0 / 0$ & $1 / 1$ & $3 / 1$ \\
\hline Largest plaque per patient & $8 / 17$ & $5 / 13$ & $0 / 0$ & $1 / 2$ & $2 / 2$ \\
\hline
\end{tabular}

in the aorta is accompanied by augmented aortic wall stiffness, which can also be assessed by TEE in terms of aortic strain [7]. Aortic stiffness is known to be an important determinant of increased systolic blood pressure and pulse pressure with age [8], and may be an independent risk factor for ischemic stroke in the elderly, regardless of whether or not aortic plaques are detected by TEE [9].

The blood flow pattern in the aortic arch is complex due to the location of its branching points to the brain, heart and other systemic vasculature as direct recipient organs, each with unique hemodynamic characteristics. Retrograde aortic blood flow during diastole contributes to the coronary and cerebral circulations, which themselves display antegrade flow during the whole cardiac cycle $[10,11]$. However, retrograde flow in the aortic arch may also lead to retrograde embolization from the distal aortic arch or the upper part of the descending aorta, where atherosclerotic plaques are frequently found [12].

The purpose of this study was to examine whether retrograde aortic flow occurs and what aortic characteristics are associated with it, in a select group of subjects undergoing TEE.

\section{Methods}

\section{Study Population}

We recruited 56 patients (table 1) on the basis of the following criteria:

(1) The ultrasound examination of the patient had to be performed by one experienced investigator and be complete with respect to the blood flow velocity profiles of interest.
(2) The angle between the Doppler transecting line and the assumed flow direction had to be small enough to enable highquality antegrade and retrograde flow signals.

(3) The quality of the image and Doppler signal had to be acceptable and the patient should have no significant aortic regurgitation.

Of the 56 patients, complex aortic plaques ( $\geq 4 \mathrm{~mm}$ with or without mobile component) were diagnosed in 17 (table 1). We found no plaque $<4 \mathrm{~mm}$ with a mobile component. The blood pressure was measured in all patients (considered high if the systolic blood pressure was $>140 \mathrm{~mm} \mathrm{Hg}$ or the diastolic blood pressure $>90 \mathrm{~mm} \mathrm{Hg}$ ). The study was approved by the Ethics Committee at Göteborg University and all subjects gave their informed consent.

\section{Transesophageal Echocardiography}

The examinations were performed using multiplane TEE (Sequoia, Siemens Medical Solutions, Ultrasound Division, Mountain View, Calif., USA, and Vivid 7, General Electrics, Milwaukee, Wisc., USA). All examinations were performed by one and the same experienced physician and digitally stored on MO disks (primarily or from S-VHS-tape).

From a 4-chamber position, the aortic valve and ascending aorta were studied in 135-degree views for the presence and location of plaques. The transducer was then rotated to visualize the descending aorta in the longitudinal view $\left(90^{\circ}\right)$ and transverse $\left(0^{\circ}\right)$ sections (fig. 1, position 2) until the appearance of the left subclavian artery, which was studied at around $45^{\circ}$. The aortic arch was carefully scrutinized for plaques in the transverse and longitudinal views, and in the latter the flow profile was studied by color Doppler (fig. 1, position 1). Color-guided pulse wave spectral Doppler velocities were obtained as parallel to the flow as possible.

Measurements were made off line using an Echopac workstation or on the ultrasound platform. The flow profiles in both systole and diastole (fig. 2a) were outlined manually to measure the maximum flow velocity and the velocity-time integrals (VTI). 
Fig. 1. TEE position 1 shows measurement point for evaluation of flow reversal, and TEE position 2 shows location of stiffness evaluation. Anatomy illustrated by magnetic resonance image to the right. $\mathrm{T}=$ Transducer; $\mathrm{E}=$ esophagus.
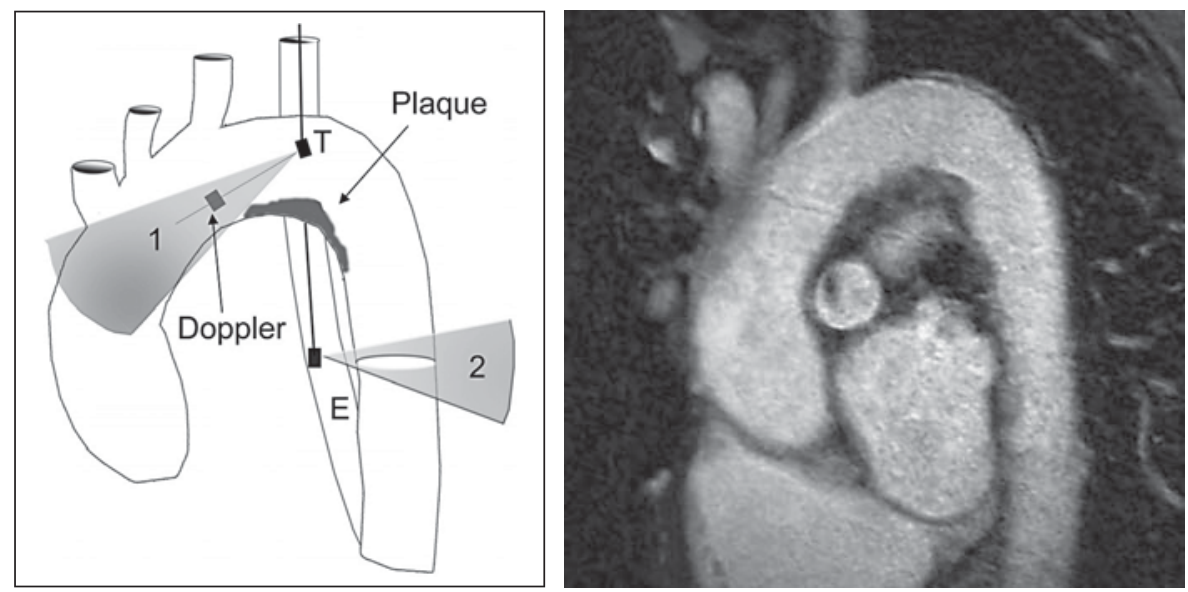

Three consecutive heart beats were measured and the mean diastolic/systolic ratio was calculated. The prevalence and distribution of aortic plaques were noted.

Further, aortic distensibility [13] was evaluated from systolic and diastolic short-axis images of the descending thoracic aorta (fig. 1, position 2). The trailing-edge to leading-edge technique was used to measure the aortic luminal area by circular regions of interest placed between the calipers to outline the aortic lumen (fig. 2b). Aortic strain was assessed as $(\chi S A-\chi D A) / \chi D A$, where $\chi \mathrm{SA}$ is the 3-heart-beat average of the aortic luminal area in systole and $\chi \mathrm{DA}$ the corresponding average area in diastole.

\section{Statistics}

Values are presented as mean values $\pm \mathrm{SD}$. The significance of differences between groups was tested using Student's t test. Pearson's linear correlation coefficients and Fisher's test were computed to illustrate relationships. $\mathrm{p}<0.05$ was regarded as significant.

\section{Results}

\section{Prevalence and Distribution of Aortic Plaques}

The 25 patients with aortic plaque were 69 years \pm 8 years of age on average (age range 46-82 years). Among these 25 patients ( 10 women), 39 of 75 (i.e. $25 \times 3$ regions) possible regions contained detectable plaques. Plaques were most commonly detected in the patients with a suspected ischemic stroke, 43\% (13/30) of whom had aortic plaques of $\geq 4 \mathrm{~mm}$, mainly in the aortic arch (table 1). The presence of plaques increased significantly with age $(\mathrm{p}<0.0001)$.

The locations of the 39 plaques among the 25 patients with aortic plaques were as follows: 4 in the ascending aorta, 20 in the arch and 15 in the descending aorta. Eight patients had plaques in more than 1 region (6 in 2 regions,
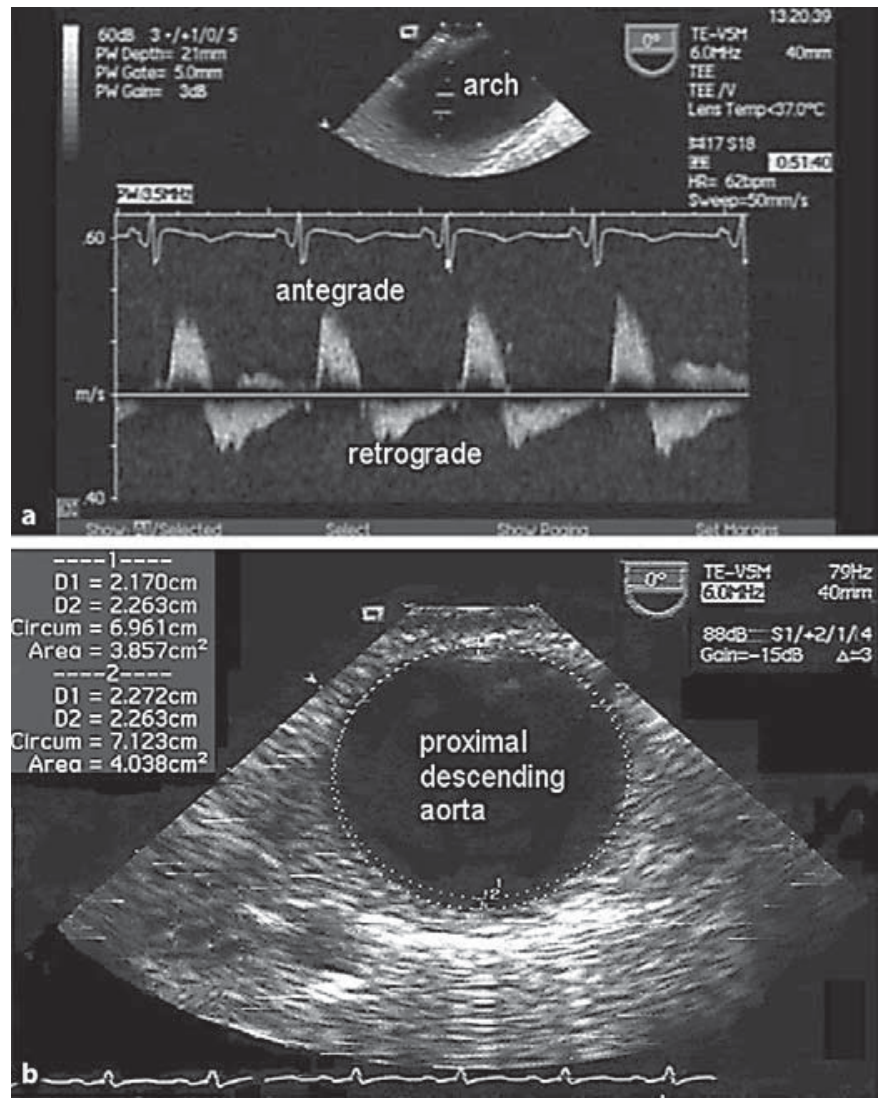

Fig. 2. a Pulsed-Doppler fast-Fourier transformation of blood flow velocities within a TEE image of the aortic arch. VTI was measured from the profiles of the systolic (antegrade) and, in this case large, diastolic (retrograde) flow. b Example of area measurements used for strain calculation within a transverse 2-dimensional TEE image of upper descending aorta. The image is end systolic, but also shows the diastolic outline, and the small difference indicates low strain. $\mathbf{a}, \mathbf{b}$ are compatible with findings in patients with arch plaques (fig. 3). 

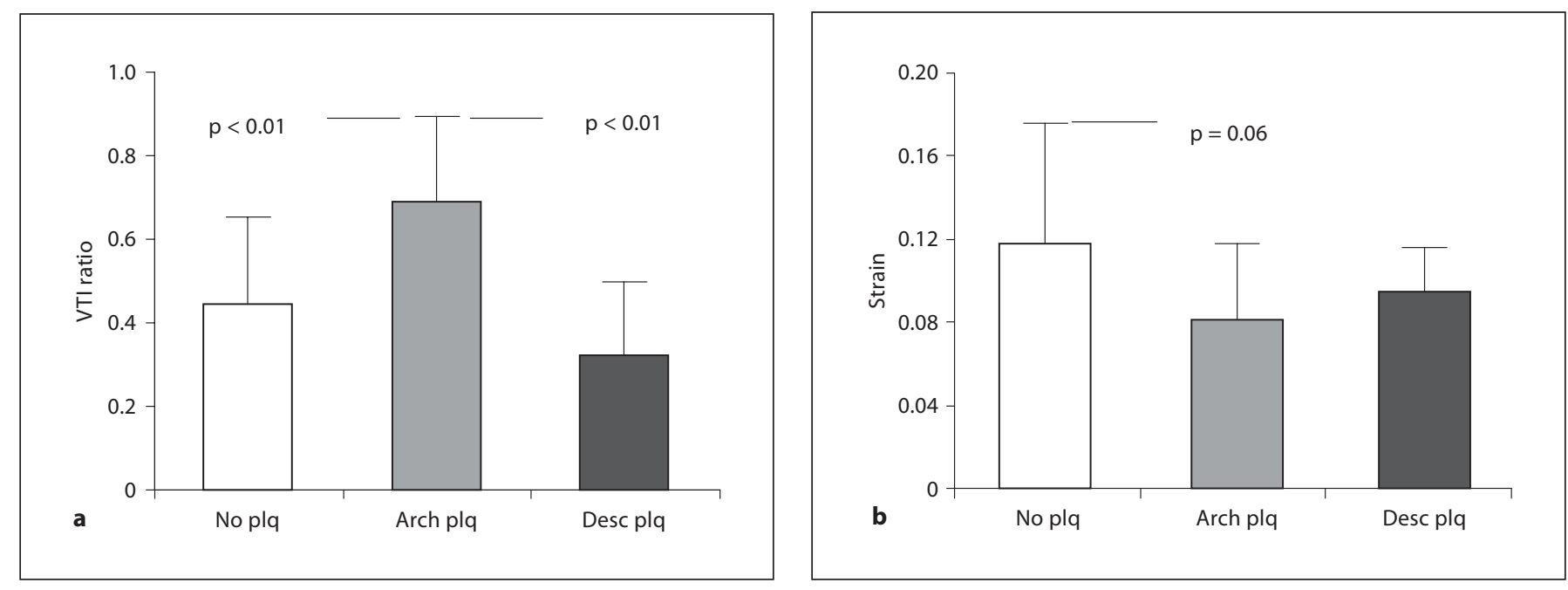

Fig. 3. a Retrograde/antegrade flow VTI ratios in the aortic arch (position 1 in fig. 1) shown for patients with no plaques (No plq), plaque in the aortic arch (Arch plq) and plaques in the descending aorta (Desc plq). b Strain of upper descending aorta (position 2 in fig. 1) in relation to the presence and location of plaques as in a above. Mean values and standard deviations.

Table 2. Aortic strain and the VTI ratio in relation to age, blood pressure and reason for referral

\begin{tabular}{|c|c|c|c|c|c|c|}
\hline & \multicolumn{2}{|l|}{ Age } & \multicolumn{2}{|l|}{ Blood pressure } & \multicolumn{2}{|l|}{ Referral reason } \\
\hline & $\begin{array}{l}<50 \text { years } \\
(\mathrm{n}=14)\end{array}$ & $\begin{array}{l}\geq 50 \text { years } \\
(\mathrm{n}=42)\end{array}$ & $\begin{array}{l}\text { no hypertension } \\
(\mathrm{n}=40)\end{array}$ & $\begin{array}{l}\text { hypertension } \\
(\mathrm{n}=16)\end{array}$ & $\begin{array}{l}\text { embolic source } \\
(\mathrm{n}=30)\end{array}$ & $\begin{array}{l}\text { other } \\
(n=26)\end{array}$ \\
\hline Aortic strain & $0.15 \pm 0.06$ & $0.10 \pm 0.05^{*}$ & $0.11 \pm 0.06$ & $0.11 \pm 0.05$ & $0.10 \pm 0.05$ & $0.11 \pm 0.06$ \\
\hline VTI ratio & $0.41 \pm 0.24$ & $0.52 \pm 0.21$ & $0.51 \pm 0.25$ & $0.47 \pm 0.16$ & $0.53 \pm 0.23$ & $0.45 \pm 0.21$ \\
\hline
\end{tabular}

${ }^{*} \mathrm{p}<0.01$ in comparison to those $<50$ years.

and 2 in 3 regions). There was no significant difference between the arch and the descending aorta in terms of plaque prevalence. A total of 21 regions in 17 patients contained plaques of $\geq 4 \mathrm{~mm}$.

\section{Blood Flow Velocity Measurements}

Some degree of diastolic retrograde flow within the aortic arch was observed in all 56 patients, and the corresponding VTI ratios, which did not change significantly with age or blood pressure, are shown in table 2 . Patients with plaques at any location $\geq 4 \mathrm{~mm}$ had a higher VTI ratio compared to those without such plaques $(0.60$ \pm 0.23 vs. $0.45 \pm 0.21, \mathrm{p}<0.05)$. However, there was a difference depending on plaque location. In patients with plaques within the aortic arch, the VTI ratios were sig- nificantly higher than among those with no plaque or plaques only in the descending aorta (fig. 3a).

\section{Measurements of Aortic Stiffness}

Aortic strain was significantly lower $>50$ years of age than below $(\mathrm{p}<0.01)$ (table 2$)$, which indicates a stiffer aorta. Pulse pressure also increased significantly with age $(p=0.002)$. Independently of age, patients with plaques in the aortic arch tended to have lower strain values in the descending aorta $(\mathrm{p}=0.06)$, in the direction of a stiffer aorta (fig. 3b). Increasing systolic and diastolic aortic dimensions were significantly related to increasing blood pressure $(\mathrm{p}<0.005)$. 


\section{Discussion}

To our knowledge, the present study represents the first attempt at TEE-based Doppler quantification of the diastolic retrograde blood flow components within the aortic arch with various degrees of atherosclerotic vessel wall abnormalities. In all study subjects, we found a retrograde aortic arch blood flow, which varied with the presence and distribution of atherosclerotic lesions. $\mathrm{Pa}$ tients with plaques in the aortic arch not only had the closeness of plaque to the cerebral artery orifices, but also had a significantly increased diastolic flow reversal, and consequently a higher risk of retrograde cerebral embolization.

TEE has been suggested as the standard method to visualize the aortic arch [14-17]. TEE is a moderately invasive technique, and a transcutaneous approach has been applied for evaluation of plaque in the aortic arch [18]. Despite improvement in transthoracic ultrasound techniques [19], TEE still gives a more secure visualization of the aortic arch in our hands in most cases. It has a high spatial and temporal resolution, compares favorably with magnetic resonance evaluations [20], and is often more readily available. However, it should be emphasized that TEE does not allow full visualization of the upper part of the ascending aorta due to the interposition of the trachea.

Under normal conditions, retrograde aortic flow occurs in the ascending aorta in diastole as a support for the coronary artery blood flow. Increased blood flow reversal is seen in cases of aortic regurgitation [21], which, in severe regurgitation, may involve the descending aorta [22]. In elderly patients without aortic valve regurgitation, but with stroke and systemic embolism, retrograde diastolic blood flow components have also been observed by means of the motion pattern of mobile aortic plaque formations [23]. Even normal children often have a short period of diastolic aortic flow reversal, although it is not evenly distributed along the aorta or within a transverse section [24]. We were able to demonstrate the existence and relative magnitude of retrograde diastolic blood flow at a critical location. In our patients, the antegrade and retrograde blood flow velocities, as well as the VTI, were calculated from the spectral Doppler signal.

Retrograde blood flow components were shown in all patients, i.e. not only in stroke patients, but also in those with other diagnoses. This implies that cerebral embolism from plaques located distally to the origin of the cerebral arteries is theoretically possible in most subjects.
In this study, we used Doppler signals to calculate blood flow velocities in the retrograde and antegrade directions. When choosing this method, we were aware of the fact that no evaluation of complex flow patterns such as rotational flow or vorticity could be made. However, our aim was to evaluate the prevalence and proportion of retrograde flow and not the precise spatial flow pattern. Absolute flow is underestimated by Doppler ultrasonography when not parallel to the ultrasound beam. We calculated the retrograde/antegrade flow ratio to minimize this problem.

We found an increased proportion of flow reversal in patients with plaque formations in the aortic arch compared to those with plaque in the descending aorta, whose flow reversal did not deviate significantly from those with no plaques.

By 4-dimensional magnetic resonance mapping, increased retrograde velocities have been demonstrated in coronary artery disease patients as well as in the elderly compared to young subjects [4]. As the arterial walls become increasingly stiffer with age, systolic lumen expansion or the possibility to store blood during systole declines [25]. This so-called 'windkessel effect' is dependent on aortic compliance and acts like a systolic blood reservoir, which in diastole propels the stored blood in the direction of lowest resistance. Thus, the capacity to be a reservoir for systolic blood volume, which can be mobilized in diastole, is lost with the development of atherosclerosis. This leads to increased systolic pressure and the augmentation of pulse pressure [26], higher left-ventricular work load and secondary myocardial hypertrophy, as well as a more pulsatile blood flow pattern. In addition, it has been suggested that the diastolic blood flow and pressure are related not only to the windkessel effect, but also to the returning pressure wave reflected in peripheral arteries and resistance vessels [27]. The sites of atherosclerotic plaque deposition are thought to be influenced by local blood flow patterns $[28,29]$. It has also been suggested that vortices near the aortic wall, and helical and reversed flow influence the shear stress and may be important in atherogenesis in both animals and humans [30]. The stability of helical flow in the ascending aorta is thought to spare this region, while the relatively unstable flow pattern in the distal arch and proximal descending aorta seems to predispose to atherogenesis [10, 31]. This predilection site for plaques, in combination with an increased flow reversal among those with arch plaques such as we have shown, might cause a high-risk situation for retrograde embolization. A crude odds ratio of 5.5 for ischemic stroke in case of plaque $\geq 4 \mathrm{~mm}$ situ- 
ated in the distal arch (distal to the left subclavian artery) supports this assumption [5].

In conclusion, a diastolic retrograde flow component was present in the aortic arch of all the examined subjects. This phenomenon could facilitate retrograde embolization to the brain from vulnerable plaques located in the aorta distally to the precerebral arteries. We therefore suggest that complex plaques situated in the distal aortic arch are considered a potential source of cerebral emboli.

\section{Acknowledgements}

This study was supported by the Swedish Medical Research Council (14231), the Swedish Heart and Lung Foundation, and grants from the Swedish state under the LUA/ALF agreement, the Health and Medical Care Executive Board of the Region Västra Götaland, the Göteborg Medical Society, and the Swedish Stroke Association.

The authors are grateful to the staff at the Department of Clinical Physiology, Sahlgrenska University Hospital, Göteborg, for assistance with the ultrasound investigations; to Dr. Michael Broomé, Karolinska University Hospital, for valuable discussions on aortic circulation; to Prof. Eva Forssell Aronsson and Ms. Susanne Ribbelin, Göteborg University, for providing the magnetic resonance image; Mr. Lo Caidahl, Göteborg, and Ms. Eva LinderKlingsell, Karolinska Institutet, Stockholm, Sweden, for technical assistance with figure 1 .

\section{References}

1 Li C, Engstrom G, Janzon L, Hedblad B: Long-term stroke prognosis in relation to medical prevention and lifestyle factors. A prospective population-based study. Cerebrovasc Dis 2008;25:526-532.

$\checkmark 2$ Sun N, Wood NB, Hughes AD, Thom SA, Yun $\mathrm{Xu} \mathrm{X}$ : Effects of transmural pressure and wall shear stress on LDL accumulation in the arterial wall: a numerical study using a multilayered model. Am J Physiol Heart Circ Physiol 2007;292:H3148-H3157.

3 Malek AM, Alper SL, Izumo S: Hemodynamic shear stress and its role in atherosclerosis. JAMA 1999;282:2035-2042.

-4 Bogren HG, Buonocore MH, Valente RJ: Four-dimensional magnetic resonance velocity mapping of blood flow patterns in the aorta in patients with atherosclerotic coronary artery disease compared to agematched normal subjects. J Magn Reson Imaging 2004;19:417-427.

-5 Amarenco P, Cohen A, Tzourio C, Bertrand B, Hommel M, Besson G, Chauvel C, Touboul PJ, Bousser MG: Atherosclerotic disease of the aortic arch and the risk of ischemic stroke. N Engl J Med 1994;331:1474-1479.

-6 Tanaka M, Yasaka M, Nagano K, Otsubo R, $\mathrm{Oe} \mathrm{H}$, Naritomi H: Moderate atheroma of the aortic arch and the risk of stroke. Cerebrovasc $D$ is 2006;21:26-31.

-7 Nishino M, Masugata H, Yamada Y, Abe H, Hori M, Kamada T: Evaluation of thoracic aortic atherosclerosis by transesophageal echocardiography. Am Heart J 1994; 127: 336-344.

8 Dernellis J, Panaretou M: Aortic stiffness is an independent predictor of progression to hypertension in nonhypertensive subjects. Hypertension 2005;45:426-431.
Sugioka K, Hozumi T, Sciacca RR, Miyake Y, Titova I, Gaspard G, Sacco RL, Homma S, Di Tullio MR: Impact of aortic stiffness on ischemic stroke in elderly patients. Stroke 2002 33:2077-2081.

10 Bogren HG, Buonocore MH: Blood flow measurements in the aorta and major arteries with MR velocity mapping. J Magn Reson Imaging 1994;4:119-130.

11 Bogren HG, Klipstein RH, Firmin DN, Mohiaddin $\mathrm{RH}$, Underwood SR, Rees RS, Longmore DB: Quantitation of antegrade and retrograde blood flow in the human aorta by magnetic resonance velocity mapping. Am Heart J 1989;117:1214-1222.

12 Khoury Z, Gottlieb S, Stern S, Keren A: Frequency and distribution of atherosclerotic plaques in the thoracic aorta as determined by transesophageal echocardiography in patients with coronary artery disease. Am J Cardiol 1997;79:23-27.

13 O'Rourke MF, Staessen JA, Vlachopoulos C, Duprez D, Plante GE: Clinical applications of arterial stiffness: definitions and reference values. Am J Hypertens 2002;15:426444.

14 Tunick PA, Kronzon I: Protruding atherosclerotic plaque in the aortic arch of patients with systemic embolization: a new finding seen by transesophageal echocardiography. Am Heart J 1990;120:658-660.

15 Tunick PA, Perez JL, Kronzon I: Protruding atheromas in the thoracic aorta and systemic embolization. Ann Intern Med 1991;115: 423-427.

16 Toyoda K, Yasaka M, Nagata S, Yamaguchi T: Aortogenic embolic stroke: a transesophageal echocardiographic approach. Stroke 1992;23:1056-1061.
17 Horowitz DR, Tuhrim S, Budd J, Goldman ME: Aortic plaque in patients with brain ischemia: diagnosis by transesophageal echocardiography. Neurology 1992; 42: 1602-1604.

18 Weinberger J, Azhar S, Danisi F, Hayes R, Goldman M: A new noninvasive technique for imaging atherosclerotic plaque in the aortic arch of stroke patients by transcutaneous real-time B-mode ultrasonography: an initial report. Stroke 1998;29:673-676.

19 Caidahl K, Kazzam E, Lidberg J, Neumann Andersen G, Nordanstig J, Rantapaa Dahlqvist S, Waldenstrom A, Wikh R: New concept in echocardiography: harmonic imaging of tissue without use of contrast agent. Lancet 1998;352:1264-1270.

20 Kutz SM, Lee VS, Tunick PA, Krinsky GA, Kronzon I: Atheromas of the thoracic aorta: A comparison of transesophageal echocardiography and breath-hold gadolinium-enhanced 3-dimensional magnetic resonance angiography. J Am Soc Echocardiogr 1999; 12:853-858.

-21 Ambrosi P, Faugere G, Desfossez L, Habib G, Bory M, Luccioni R, Bernard P: Assessment of aortic regurgitation severity by magnetic resonance imaging of the thoracic aorta. Eur Heart J 1995; 16:406-409.

-22 Sutton DC, Kluger R, Ahmed SU, Reimold SC, Mark JB: Flow reversal in the descending aorta: a guide to intraoperative assessment of aortic regurgitation with transesophageal echocardiography. J Thorac Cardiovasc Surg 1994;108:576-582.

23 Tenenbaum A, Motro M, Feinberg MS, Schwammenthal E, Stroh CI, Vered Z, Fisman EZ: Retrograde flow in the thoracic aorta in patients with systemic emboli: a transesophageal echocardiographic evaluation of mobile plaque motion. Chest 2000;118:17031708 . 
-24 Fogel MA, Weinberg PM, Haselgrove J: Nonuniform flow dynamics in the aorta of normal children: a simplified approach to measurement using magnetic resonance velocity mapping. J Magn Reson Imaging 2002;15: 672-678.

-25 Nagai Y, Helwegen J, Fleg JL, Beemer MK, Earley CJ, Metter EJ: Associations of aortic Windkessel function with age, gender and cardiovascular risk factors. Ultrasound Med Biol 2001;27:1207-1210.
26 Dart AM, Kingwell BA: Pulse pressure - a review of mechanisms and clinical relevance. J Am Coll Cardiol 2001;37:975-984.

27 Laffon E, Galy-Lacour C, Laurent F, Ducassou D, Marthan R: MRI quantification of the role of the reflected pressure wave on coronary and ascending aortic blood flow. Physiol Meas 2003;24:681-692.

-28 Farthing S, Peronneau P: Flow in the thoracic aorta. Cardiovasc Res 1979;13:607-620.

-29 Kilner PJ, Yang GZ, Mohiaddin RH, Firmin $\mathrm{DN}$, Longmore DB: Helical and retrograde secondary flow patterns in the aortic arch studied by three-directional magnetic resonance velocity mapping. Circulation 1993; 88:2235-2247.
30 Frazin LJ, Vonesh MJ, Chandran KB, Shipkowitz T, Yaacoub AS, McPherson DD: Confirmation and initial documentation of thoracic and abdominal aortic helical flow. An ultrasound study. Asaio J 1996;42:951-956.

31 Hueb JC, Zanati SG, Okoshi K, Raffin CN, Silveira LV, Matsubara BB: Association between atherosclerotic aortic plaques and left ventricular hypertrophy in patients with cerebrovascular events. Stroke 2006;37:958962. 